CUADERNOS DE ESTUDIOS GALLEGOS, LVIII N. ${ }^{\circ} 124$, enero-diciembre (2011), pp. 235-252

ISSN 0210-847 X

\title{
LAS CASAS SOLARIEGAS DE LA HIDALGUÍA GALLEGA. ESTUDIO SOBRE LAS CASAS DE LOS CONDES DE AMARANTE EN EL SIGLO XVIII
}

AnASTASIO S. Iglesias Blanco

Universidad de Santiago de Compostela. 


\title{
LAS CASAS SOLARIEGAS DE LA HIDALGUÍA GALLEGA. ESTUDIO SOBRE LAS CASAS DE LOS CONDES DE AMARANTE EN EL SIGLO XVIII
}

\begin{abstract}
RESUMEN
El enriquecimiento de la hidalguía gallega durante la época moderna se reflejaría, entre otros aspectos, en su asentamiento en núcleos urbanos, quedando sus antiguas casas solariegas, con escasas excepciones, en manos de sus administradores, de algunos de sus caseros o totalmente deshabitadas. En este artículo se analiza el ejemplo concreto de las casas acumuladas por los condes de Amarante a lo largo de la época moderna, en las que se realizarían importantes obras en diversos momentos del siglo XVIII, aunque las mayores inversiones se concentrarían en aquellos edificios en donde los condes residían junto con sus familias.
\end{abstract}

PALABRAS ClAVE: Hidalguía gallega, proceso de urbanización, casas solariegas, condes de Amarante, siglo XVIII, obras y reparos.

\section{THE HOMESTEADS OF THE GALICIAN NOBILITY. STUDY ABOUT THE COUNTS OF AMARANTE'S HOUSES IN THE $18^{\mathrm{TH}}$ CENTURY}

\begin{abstract}
The enrichment of the Galician nobility during the Modern epoch would be reflected, among other things, on their settlement in urban areas, leaving their old homesteads, with few exceptions, in the hands of their administrators, of their householders or totally uninhabited. In this article we analize the specific example of the houses accumulated by the counts of Amarante along the modern epoch, in which major works would be carried out at various times of the eighteenth century, although major investments would be concentrated in those buildings where the counts were residing with their families.
\end{abstract}

KEY WORDS: Galician nobility, process of urbanization, homesteads, counts of Amarante, $18^{\text {th }}$ century, works and repairs. 
Recibido/Received: 28/09/2010

Aceptado/Accepted: 27/07/2011

$\mathrm{D}$

URANTE la época moderna se desarrollaría un intenso proceso de urbanización de la hidalguía gallega más rica y poderosa, la cual abandonaría las casas solariegas que poseía en el ámbito rural para instalarse en edificios ubicados en las principales villas y ciudades de Galicia e, incluso, en urbes castellanas, como Valladolid o Salamanca, así como en Madrid, villa en la que fijarían su residencia, temporal o permanentemente, aquellos hidalgos con empleos militares, administrativos o cortesanos de relevancia que exigían su presencia en la Corte ${ }^{1}$. Esta hidalguía absentista, tal y como había sucedido a comienzos de la Edad Moderna con la alta nobleza gallega, dejaría sus antiguas casas solariegas en manos de administradores y mayordomos de rentas, convertidos en sus principales y, en muchos casos, únicos habitantes, transformándose, así, en simples centros administrativos en los que dichos administradores y mayordomos se encargaban de percibir y comercializar las rentas de sus titulares, remitiendo a éstos las cantidades en metálico que obtenían con ello, una vez descontados sus gastos de administración. En cambio, las casas en donde residía esta hidalguía se encontraban llenas de vida, con la presencia de un gran número de sirvientes, y sus múltiples estancias estaban muy bien amuebladas y profusamente decoradas ${ }^{2}$.

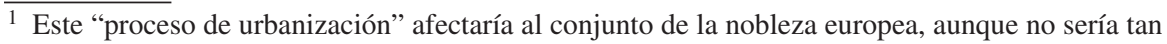
intenso como en España o Italia. Vid.: BUSH, Michael L., Rich noble, poor noble, Manchester 1988, 153-64; y, para la hidalguía de Galicia, SAAVEDRA FERNÁNDEZ, Pegerto, "Formación, consolidación e influencia social e cultural da fidalguía, séculos XVI-XVIII", Galicia fai dous mil anos. O feito diferencial galego 1, Santiago de Compostela 1997, 137-39.

2 Aunque todavía son escasos, en los últimos años se han publicado diversos trabajos sobre la vida cotidiana y la cultura material en los pazos gallegos. Entre ellos, vid.: SAAVEDRA FERNÁNDEZ, Pegerto, "A vida cotiá da fidalguía pacega", Un percorrido pola Galicia cotiá, Santiago de Compostela 1998, 373-96; ídem, "La vida en los pazos gallegos: entre la literatura y la historia", $\mathrm{Pe}$ dralbes. Revista d'historia moderna, 23 (2003), 285-315; PRESEDO GARAZO, Antonio, "Luxo e cultura nos pazos da fidalguía galega, 1600-1841”, Boletín Auriense, 31 (2001), 143-64; ídem, Dueños y señores de casas, torres y pazos: 1500-1900 (Contribución al estudio de la fidalguía gallega), Tesis doctoral inédita, Santiago, 2001, 469-547; MIGUÉS RODRÍGUEZ, Vitor Manuel, As terras, as pousas e os vinculeiros. A fidalguía galega na Época Moderna, Sada-A Coruña, 2002, 337-88; y, para el siglo XIX, DOMINGUEZ CASTRO, Luís, "A fidalguía na sociedade do século
} 
En este trabajo se pretende analizar la situación en la que se hallaban las casas solariegas que acabarían en poder de los condes de Amarante durante el siglo XVIII, la mayoría de ellas agregadas como consecuencia de la falta de descendencia de algunos de sus titulares. Así, fallecidos sin hijos don Juan López de Lemos, que había recibido el título de conde de Amarante en 1648, y su hermano don Pedro López de Lemos, sus casas pasarían al hijo de una hermana, don García Ozores, que también heredaría de su padre las casas de Teanes y Covelo. Este señor fallecería en 1712, también sin hijos, siendo sucedido por su hermana doña Juana Ozores, fallecida en 1713, y por el hijo de ésta, don Pedro Arias Ozores, que también heredaría el marquesado de San Miguel de Penas. Éste no se casaría y en 1718 sus casas recaerían en su hermana, doña Constanza Arias Ozores, que se casaría con don Andrés de Gayoso y Neira, señor de Oca. El hijo y heredero de estos dos señores, don Fernando Gayoso, se casaría con doña María Josefa de los Cobos, heredera, por muerte de su hermana mayor, del marquesado de la Puebla de Parga. Por último, el hijo de éstos, don Domingo Gayoso, además del condado de Amarante y los marquesados de San Miguel y Parga, también heredaría, por muerte de dos de sus tíos en 1776 y 1791, el condado de Ribadavia y el marquesado de Camarasa, con los condados de Ricla y Castrogeriz ${ }^{3}$.

La documentación utilizada para conocer el estado de conservación de las casas heredadas por los condes de Amarante en territorio gallego a lo largo del siglo XVIII procede del Fondo Camarasa del Archivo de la Fundación Ducal de Medinaceli, que ha sido consultado en el Archivo Histórico Universitario de Santiago (AHUS), donde se conserva una copia en formato microfilm. En concreto, la mayoría de los datos de este trabajo proceden, principalmente, de tres tipos de documentación: en primer lugar, los testamentos de los condes, algunos de los cuales incluían información relevante sobre la conservación de sus casas solariegas ${ }^{4}$; en segundo lugar, las contabilidades rendidas anualmente por sus administradores y mayordomos de rentas, junto con los justificantes que presentaban con ellas, en donde quedaban registradas las

XIX", Galicia fai dous mil anos. O feito diferencial galego 1, Santiago, 1997, 157-79; ídem, "Mesa farta, bodega franca, bolsa aberta: A vida cotiá da fidalguía galega no século XIX", Un percorrido pola Galicia cotiá, Santiago, 1998, 449-73.

3 Sobre el linaje de los condes de Amarante, cf.: FERNÁNDEZ DE HENESTROSA, Ignacio, Apuntes para el historial de la Casa de Camarasa, San Sebastián 1934, 209-49; CRESPO DEL POZO, José, Blasones y linajes de Galicia 3, Santiago 1985, 162-66; e IGLESIAS BLANCO, Anastasio S., La casa de Amarante: siglos XVI-XIX, Santiago 2009, 17-40.

4 No obstante, los testamentos han sido utilizados, principalmente, para estudiar las actitudes de la nobleza ante la muerte y, en menor medida, la relación que mantenían con sus sirvientes. Vid., para el primer caso, BARREIRO MALLÓN, Baudilio, "La nobleza asturiana ante la muerte y la vida", Actas del II Coloquio de Metodología Histórica Aplicada. La Documentación Notarial y la Historia 2, Santiago 1984, 27-60; y, para el estudio de la servidumbre, MIGUÉS RODRÍGUEZ, Vitor Manuel, As terras, as pousas e os vinculeiros, 79-87. 
sumas invertidas durante el siglo XVIII en las obras realizadas en dichos edificios ${ }^{5}$; $\mathrm{y}$, por último, los inventarios postmortem, que recogían los bienes que estos condes poseían en sus residencias, siendo especialmente completos y precisos los inventarios hechos a mediados del siglo XVIII, tras la muerte de don Fernando Gayoso ${ }^{6}$.

\section{LAS CASAS A INICIOS DE SIGLO}

El estado de conservación de la mayor parte de las casas que poseían los condes de Amarante a inicios del siglo XVIII dejaba mucho que desear, pues los mayordomos que residían en ellas tan sólo ocupaban una mínima parte de sus estancias, que solían ser las que mejores condiciones presentaban, junto con aquellas otras en las que se hallaban las paneras, tullas, lagares o bodegas en donde se recogían las rentas percibidas en especie, que eran la mayor parte. En algunas casas ni siquiera existía un mayordomo que habitase en ellas, quedando al cuidado de los "caseros" que residían en alguno de los edificios anexos o en sus proximidades, razón por la que sus puertas se abrían casi exclusivamente en las épocas del año en que se percibían las rentas ${ }^{7}$. Los señores, por su parte, tan sólo visitaban estos edificios ocasionalmente, sobre todo con motivo de sus viajes, y algunos de ellos ni siquiera llegarían a conocer sus muros: así, don Pedro Arias Ozores, aunque en el año 1708 había tomado posesión personalmente de las casas que formaban parte del marquesado de San Miguel de Penas, parece que nunca visitaría sus posesiones del condado de Amarante, tal y como señalaban algunos de sus vasallos de Amarante tras su muerte, atribuyendo su mal estado de conservación a las "ausencias" de este señor y de sus dos antecesores ${ }^{8}$.

De esta misma opinión era don Andrés de Gayoso, que en 1720 solicitaba ante la Real Audiencia de Galicia el reconocimiento y valoración de los desperfectos

\footnotetext{
${ }^{5}$ La utilización de las contabilidades nobiliarias para el estudio de la vida cotidiana en los pazos gallegos ya ha dado resultados interesantes. Vid., por ejemplo, GARCÍA ACUÑA, M. ${ }^{\text {a } L u i s a, ~ " A ~}$ forma de vida nobre na Galicia do século XVIII a través do condado de Ribadavia", Actas do V Congreso Internacional de Estudios Galegos 1, Sada-A Coruña 1997, 237-53; y PRESEDO GARAZO, Antonio, "O luxo na fidalguía galega a través do exemplo da Casa-Torre de Raíndo, 17981800", Homenaxe ó profesor Manuel Quintáns, Santiago 1999, 183-207.

${ }^{6}$ Sobre el uso de los inventarios para conocer la cultura material de los pazos, vid.: SAAVEDRA FERNÁNDEZ, Pegerto, "Formación, consolidación e influencia social e cultural da fidalguía", 12347; y, también, PRESEDO GARAZO, Antonio, A Fidalguía Galega. Estudos sobre a reproducción social dos fidalgos na Galicia Moderna, Santiago 2008, 91-120.

7 Era una situación que también se encontraba en otras casas de la nobleza peninsular, como el palacio de los duques de Feria en la villa extremeña de Zafra, que era el centro administrativo de todo su ducado, pero estaba "bajo mínimos". Vid.: ARAGÓN MATEOS, Santiago, El señor ausente: el señorío nobiliario en el Setecientos, Lleida 2000, 35 ss.

8 AHUS, Medinaceli, Amarante, [Microfilm] 480, leg. 15, doc. 2 (Tomas de posesión); y 488, leg. 22, doc. 1 (Testamentaría de don Pedro Arias Ozores).
} 
existentes en aquellas casas que debía heredar su esposa, doña Constanza Arias Ozores, para que la cantidad resultante fuese repartida entre todos los herederos de los señores don García Ozores, doña Juana Ozores y don Pedro Arias Ozores:

[...] en el tiempo que fueron subcesores y poseedores de dicho condado de Amarante y sus estados dichos don García, doña Juana y don Pedro se causaron muchas y considerables deterioraciones y menoscavos en las casas de Ferreira, Sober, Amarante, Teanes, Cubelo, granxas de Paçoshermos y Saa, San Miguel de Penas, Mota y Moreiras, y más a dichos condado y estados anexas y pertenecientes, y en sus capillas y patronatos, para cuio remedio, reparo y redificación se necesitan encrecidas cantidades, a que están sujetos y obligados todos y qualesquiera vienes fincables por muerte de dichos don García, doña Juana y don Pedro, según el ymporte de las deterioraciones causadas en cada uno de los tres tiempos [... $]^{9}$.

En concreto, según las diligencias practicadas en el año 1720 con motivo de la testamentaría de don Pedro Arias Ozores, la fortaleza de Amarante, que "demuestra, por su fábrica y paredes, mucha antigüedad", poseía un edificio principal de dos pisos, con sus respectivos cuartos y salones, y anexos a dicho edificios se hallaban un "castillo" bien conservado, una torre "de cantería labrada", que había perdido su techumbre, y una capilla consagrada a Nuestra Señora de las Nieves — próxima a la fortaleza, aunque "fuera de la portada" de ella— que, según la opinión del propio mayordomo de rentas, se conservaba "con yndezençia" 10 .

El edificio principal, en su aspecto exterior, presentaba unas ventanas de madera que estaban "biejas y derrotadas", mientras que "la mayor parte del lienço de frente a la portada de la entrada hestá caydo y arruynado, y la escina de haçia el norte havierto con grietas, amenazando ruina"; en su interior, los pisos y sobrados se encontraban "biejos y rompidos", con muchas tablas llenas de brechas, "que no se pueden pisar sin luz por el riesgo de caerse y romper las piernas", y, aunque las vigas y los puntones todavía se conservaban en buen estado y había algunas tablas nuevas que también podían servir, "es nezesaria mucha cantidad

\footnotetext{
9 Se desconocen las diligencias practicadas en virtud de la provisión real obtenida con esta solicitud — provisión fechada en Coruña el 20 de abril de 1720_, pero parece que no se conseguiría lo que don Andrés de Gayoso y su esposa pretendían. Casi veinte años después, don Fernando Gayoso, hijo de los anteriores, obtenía otra provisión —el 23 de mayo de 1737- para reconocer los desperfectos de las casas de sus padres, afirmando que "se allan mui deterioradas y arruinadas, por lo cual nezesitan de que se reparen y compongan, y a no acerlo prontamente se arruinarán del todo". Vid.: AHUS, Medinaceli, Amarante, 473, leg. 8, doc. 15 (Provisiones reales).

${ }^{10}$ Opinión confirmada por el receptor de la Real Audiencia encargado de realizar las diligencias necesarias para cumplir el testamento de don Pedro Arias Ozores. Según su reconocimiento, esta capilla "se alla sin puerta ni retablo, con solo sobre la loza del altar una caxa pequeña, viexa y tosca, y dentro la imaxen de Nuestra Señora y otras dos pequeñas, biejas, corcomidas e yndezentes, sin frontal, manteles, ara ni otra cosa"; la sacristía "abatida, sin cuvierta ni puerta"; el techo de la capilla con falta de teja y madera; y, además, no tenía cáliz, misal ni otro tipo de ornatos, pues éstos, según declaración de algunos vecinos, habían sido enviados a la capilla de la casa de Sober. AHUS, Medinaceli, Amarante, 488, leg. 22, doc. 1 (Testamentaría de don Pedro Arias Ozores).
} 
de ellas para volber a sobradar y mucha clavaçón", todo lo cual requería una inversión de "mucha suma de dinero"11. En lo tocante a su aspecto interior, su mobiliario se restringía a una media cama "de antigüedad", situada "en el quarto de la sala segunda de la cheminea", dos arcas de 36 ferrados de porte (cada una), "un bufete rompido y viejo, sin cajones, y una silla echa pedaços, que tendrá uno y otro cient años, y quedó de antigüedad". Pero, el mayordomo de rentas, por orden del señor, había aumentado este mobiliario inicial con la adquisición de "un bufete de nogal con tres cajones y dos bancos de respaldo de castaño, que se allan en la primera sala de la entrada de dicha casa"; y además, en la casa también se conservaba una arca nueva de 48 ferrados de porte y, debajo de la sala de la chimenea, en una bodega del edificio, se encontraban dos tullas o paneras, que "por ahora, aunque antiguas, están buenas y compuestas y reparadas"12.

Por su parte, la casa de San Miguel de Penas, que era la residencia habitual de su mayordomo de rentas, parece que se hallaba en mejor estado que la de Amarante, pero también tenía desperfectos considerables:

Habiendo entrado en el salón prinçipal, que tiene su serventía por el patín y correspondençia por dentro al quarto de cozina y enparexa a lo largo con la yglesia parrochial de esta feligresía, con corredor que sale a la tribuna de la capilla maior, se halló el piso y sobrada deshigual, roto y ahuxereado por haverse carcomido las tablas, que nezesita de juntarse de nuevo y añadir otras más para las faltas, que han de ser a lo menos la terçia parte y toda la clavazón, porque la que tiene, por ser muy biexa, no podrá servir, y estar apasada del orín, y las bentanas neçesitan de reparo y algunas de que se hagan otras de nuevo; en cuio salón hay un apartadizo de tabique para dormitorio o retiro, y el asiento de la lumbre de la cheminea de dicho salón está descompuesto; y otro cuarto que sale a dicho patín y al de cozina está del todo derrotado del piso y neçesita de tablado nuevo; y, siguiente a él, otro quarto con cheminea [...] se halla todo el piso deshigual, viexo y de mala calidad, con algunos remiendos, y las tres ventanas de que él salen de la guerta, sus puertas y contraventanas viejas y derrotadas, que necesitan de otras nuebas; y el quarto de cozina [necesita] de algunos reparos; y la escalera que sube a la torre [está] rompida y derrotada del todo, que necesita de una nueva; y los tres pisos de tablado [necesitan] de repararse todos, y algunas de las puertas $[\ldots]^{13}$.

11 Don Pedro Arias Ozores, informado de que "la casa está derrotada y poco falta para hazerse toda ella ynavitable", ya había ordenado comprar al administrador "veynte y seis moyos de teja y algunos tejones, que se allan en el patio de dicha casa y su fortaleza, con ánimo de que saliendo del castillo donde murió haçer componer y retexar" todo lo necesario.

12 Un mobiliario bastante escaso y, excepto el bufete y los dos bancos que había comprado el mayordomo, viejo y mal conservado, el cual no presentaba grandes diferencias con respecto a aquel que se podía encontrar en algunas viviendas del campesinado, aunque en estas últimas se concentraría en un menor espacio - la mayoría eran casas terrenas con una mínima división interna - y en lugar del bufete habría una artesa o una mesa. Sobre las características de las viviendas rurales en el interior lucense, vid.: SOBRADO CORREA, Hortensio, Las tierras de Lugo en la Edad Moderna. Economía campesina, familia y herencia, 1550-1860, Coruña 2001, 496 ss.

13 AHUS, Medinaceli, Amarante, 487, leg. 22, doc. 1 (Testamentaría del difunto señor don Pedro Arias Ozores). 
Asimismo, los bienes muebles de San Miguel de Penas eran más abundantes que los de Amarante, aunque la mayor parte también "demostraban por su antigüedad de fábrica y bexez haver quedado de los anteçesores de dicho conde don Pedro" 14 . Entre estos bienes, que se caracterizaban por hallarse "rotos" o "muy usados", había ocho camas, siete sillas — dos de ellas eran de moscovia—, cinco arcas, cuatro bufetes, tres bancos de respaldo, dos papeleras, una cama de campo, una alacena portátil y una silla de manos - sin vidrieras, sin cortinas, de moscovia y con forro de damasco negro- - . En total, eran treinta y dos muebles, a los cuales se añadían otros objetos que utilizaba el mayordomo, aunque no todos eran herencia de los antepasados de don Pedro Arias: un almirez de bronce, tres jarros de estaño y cuatro toneles existentes en la bodega de la casa — de ocho cañados cada uno- eran herencia de sus antiguos dueños, mientras que doce platos de Talavera ordinaria, dos candeleros de aramio - casi nuevos- y una tijera de espabilar "havían sido de don Benito Blanco, mayordomo y administrador de las rentas que fue de esta dicha casa" 15 .

Las casas de Moreiras y San Esteban de la Mota se encontraban en una situación similar a las anteriores. La "casa grande llamada de Moreiras" 16 estaba habitada por sus caseros, "que vivían en la cozina de dicha casa", y sus principales desperfectos se encontraban en los pisos de algunas estancias como la cocina y el cuarto situado tras ella-, en "algunas bigas de mucho porte" — como las del fallado—, en las paredes del salón grande "que hace frente al solano y travesía" - especialmente, en aquella "donde está la chaminea" - y en la pared de la fachada principal ${ }^{17}$. Por su parte, "la casa y torre

${ }^{14}$ En concreto, estos bienes eran herencia de don Sancho Arias Conde y Ulloa, el padre de don Pedro Arias Ozores, "y otros más bienes, los mexores, los había vendido y dado el marqués don Fernando Arias Ozores, hermano maior del dicho conde don Pedro". Según el mayordomo y otros testigos, en esta venta se habían incluido numerosas sillas - "las más nuevas y mejores que bestían y adornaban el salón" de la casa—, una cama "sobredorada" y otras alhajas varias que adquirieron, entre otros compradores, don Fernando Arias Noguerol, señor de la casa de Cumbraos, y Juan Vázquez, que era un "cirujano" de la propia feligresía de San Miguel de Penas. Ibíd.

15 De este mayordomo y su esposa también había la siguiente ropa de cama: dos jergones de estopa, dos colchones de estopilla y lana, un cobertor, cuatro sábanas de estopilla, dos almohadas de estopilla y dos de lienzo, y una colcha de estopilla.

16 Una casa grande sita en Santa Mariña de Fontecuberta en la que "se alla patín y escala de cantaría $\mathrm{y}$, a los lados, dos salones de lo mesmo, con su medio patio a modo de media naranja". AHUS, Medinaceli, Amarante, 488, leg. 22, doc. 1.

17 Su mobiliario se caracterizaba por su vejez y escasez, pues estaba formado tan sólo por tres bufetes, tres arcas, dos alacenas, un banco de respaldo y una silla; todo ello, además de las tullas, que se situaban debajo del salón grande. No obstante, la mayor parte de sus muebles también había sido vendido en tiempos del señor don Fernando Arias Ozores, así como la madera — robles y castaños- de una dehesa y una gran cantidad de cabezas de ganado - cuatro bueyes de labranza, alrededor de quince vacas y un mayor número de cabras, ovejas y cerdos-. Ibíd. 
de la Mota"18 era el lugar de residencia del mayordomo, que vivía "en los quartos bajos y casa de cozina", y también necesitaba reparos en los pisos de sus dos torres y de la mayoría de sus estancias, pues "sólo se halla tratable un quarto de sobrado con dos alcobas que está arrimado a la torre más alta", en sus ventanas, "por hallarse derrotadas y algunas faltosas", en el corredor que unía las torres con la casa principal y en la muralla que rodeaba al edifi$\operatorname{cio}^{19}$.

Finalmente, las granjas y la casa de Pazoshermos también atravesaban una grave situación de abandono, pues no tenían puertas ni ventanas, sus vigas estaban podridas y no se conservaba ningún tipo de mobiliario en su interior, excepto en la bodega de la casa principal. En ésta había una cuba de vino tinto de unos dieciocho moyos, con restos de vino de la cosecha de 1716, "sin que sea vino ni binagre, ediendo el olor", otra cuba de unos ocho moyos "de vino blanco revotado del todo" y dos cubetes, uno de cuatro moyos y con restos de vino blanco "pestilente" y otro que contenía un moyo de vinagre "revuelto y de ruín color"; unos utensilios que, debido al mal estado del vino que contenían, resultaban inservibles y era necesario hacer otros nuevos. El sacerdote que don Andrés de Gayoso había nombrado para administrar esta casa, así como diversos vecinos del lugar, afirmaban que esta situación se debía al presbítero don Pedro Bentura Arias Ozores, su administrador en los últimos años de vida de don Pedro Arias Ozores, que era su sobrino: así, según alguno de los labradores que trabajaron en estas granjas, dicho don Pedro Bentura "disipó y malbarató dichas granxas por no averlas cuidado y reparado como devía” y, enterado de la muerte de su sobrino, "vendió a toda prisa el vino bueno que tenía", retirándose a su curato — San Salvador de Leirado-y “dejando la casa y las granxas mui mal reparadas" 20 .

\footnotetext{
18 Una casa "con su portada y muralla alderedor, que demuestra su fábrica mucha antigüedad, con su castillete algo derrotado y dos torres, la una pequeña y otra muy alta, cubiertas y con sobrados". AHUS, Medinaceli, Amarante, 487, leg. 22, doc. 1.

19 Además de las tullas, que se situaban debajo del salón —entre las dos torres—, su mobiliario estaba formado por seis sillas — cuatro de ellas totalmente inservibles —, tres bancos — dos de ellos con respaldo-, dos bufetes, una arca y una media cama, mientras que los objetos de uso cotidiano se restringían a seis toneles, que en total portaban ochenta cañados de vino, una tina y un pilo de pisar uvas; unos bienes "de muy poco balor", que "demuestran antigüedad más de quarenta años" y que, según el mayordomo, "havían quedado de don Sancho Arias Conde" y eran los que quedaban tras la venta hecha por el señor don Fernando Arias Ozores. Ibíd.

${ }^{20}$ AHUS, Medinaceli, Amarante, 488, leg. 22, doc. 1.
} 


\section{REPARACIONES REALIZADAS DURANTE EL SIGLO}

La situación que presentaban a inicios de siglo estas casas, a las que se debían añadir Sober, Ferreira, Covelo y Teanes, ${ }^{21}$ sufriría una importante mejoría a lo largo del siglo XVIII, debido a que sus titulares, tal y como se reflejaba en las contabilidades de sus mayordomos de rentas, destinaron una parte considerable de sus ingresos a realizar "obras y reparos" en las diversas casas solariegas que acabarían formando parte de su extenso patrimonio. Esta labor reconstructora sería especialmente intensa en el caso de los señores don Fernando Gayoso y su esposa doña María Josefa de los Cobos, en particular, durante los años treinta y cuarenta; $\mathrm{y}$, posteriormente, tendría continuidad durante las tres últimas décadas del siglo, con el segundo hijo varón de este matrimonio, don Domingo Gayoso de los Cobos.

La labor que desarrollaron don Fernando Gayoso y su esposa en el transcurso de los años treinta y cuarenta, que, en realidad, era la continuación de lo que don Andrés Gayoso y doña Constanza Arias ya habían iniciado en las décadas anteriores, aparecía reflejada en el testamento de don Fernando Gayoso, otorgado por su viuda en virtud del poder que para ello había recibido ${ }^{22}$. Según el mencionado testamento, don Fernando Gayoso y su esposa habían realizado "mejoras de considerazión” en las casas de Amarante, San Miguel, La Mota, Ferreira, Pazoshermos, Meixide, Ourense, Oca y Santiago, las cuatro últimas heredadas de don Andrés de Gayoso; en las capillas de Amarante, Ferreira, Oca y Santa María Magdalena de Ourense; y en otros edificios que poseían en la ciudad de Santiago, como las "casas de Entremuros" y "la casa de la Algueria enfrente de la casa prinzipal"23.

\footnotetext{
${ }^{21}$ En lo que se refiere a estas cuatro casas, el receptor encargado de realizar las diligencias para la testamentaría de don Pedro Arias Ozores no realizaba un reconocimiento de sus desperfectos. En la casa de Teanes, pro ejemplo, tan sólo se hacía constar los bienes existentes en ella, de acuerdo con la declaración del mayordomo y de otros testigos: según el mayordomo, "en la casa principal no ay muebles algunos ni los alló en ella el año de diez y seis, que entró en la administrazión de los rayzes y sus rentas, y por ello le fue preziso hacer catre y comprar ropa para dormir, un bufete, dos bancos rasos y una arca, todo nuevo, que fabricó de horden de dicho conde"; declaración que confirmaban los demás testigos, añadiendo que "en la bodega ay la fustalla para recoxer el vino de la granxa de Teanes, con sus lagares", que ya existían en tiempos de don García Ozores.

22 Don Fernando Gayoso, "estando enfermo en cama" y en su residencia vallisoletana, otorgaría poder a favor de su esposa el día 21 de junio de 1751 para que, tras su fallecimiento, ella pudiera otorgar su testamento, de acuerdo con los deseos que le había comunicado en vida y con lo que señalaba en dicho poder; un testamento que, de acuerdo con dicho poder, sería otorgado por doña María Josefa de los Cobos en la ciudad de Valladolid el día 18 de febrero de 1752. Vid.: AHUS, Medinaceli, Amarante, 481, leg. 16, doc. 46 (Poder y testamento de don Fernando Gayoso).

23 Asimismo, don Fernando Gayoso "mejoró sus maiorazgos y diversos forales levantados y opuestos, aumentando, con las demandas y pleitos que a puesto y seguido sobre ello, partida considerable de renta, así de zenteno y trigo como dinero"; una tarea que llevaría a cabo con varios lugares y forales de las casas de Amarante, Sober y Ferreira, La Mota, Oca, Santiago y, especialmente, con "la hazienda de Cambados, Rial y Castrelo, en el valle del Salnés, y la de el partido de Goián y Arnoya, anexa y perteneziente a su casa y maiorazgo de Teanes". Ibíd.
} 
No obstante, las mayores inversiones de estos señores en "obras y reparos" se concentrarían en los edificios que poseían en los núcleos urbanos — Santiago, Coruña y Orense - y, especialmente, en aquellos "palacios" o "pazos" en donde solían residir habitualmente o que visitaban con mayor frecuencia. De acuerdo con ello, la inversión realizada por don Fernando Gayoso y su esposa en la reparación de la fortaleza de Amarante y su capilla, incluidos los ornamentos necesarios para oficiar misa en ésta, ascendía a 1.000 ducados, pero las obras realizadas para "reedificar de nuevo el jardín" de la casa principal de Santiago, el edificio existente enfrente de ella, destinado a mayordomía, y las casas de Entremuros sumaban un total de 5.000 ducados, mientras que los diversos trabajos acometidos en el pazo de Oca y su capilla habían supuesto un desembolso de 16.000 ducados.

Además, la mayoría de estas casas continuaron con un mobiliario caracterizado por su escasez y, excepto en ocasiones en las que se hizo imprescindible su renovación, por su vejez, mientras que aquellos edificios en los que residían los señores contaban con un mayor desarrollo arquitectónico y en sus numerosas estancias se encontraban abundantes objetos decorativos — cuadros, esculturas... — y de uso cotidiano — menaje de cocina... — , ropa de varios tipos — colgaduras de cama, manteles, servilletas... - y un mobiliario que reflejaba la posición social y económica de sus poseedores, por sus materiales de elaboración - castaño, nogal, cerezo, caoba... - o por su formato y su decoración - molduras, escudos... -24 .

Una muestra de la diferencia que había entre las diversas casas se puede ver en el cuadro 1, que recoge el valor de los bienes inventariados en siete de ellas tras la muerte de don Fernando Gayoso. Así, los bienes del "palacio" vallisoletano en el que había fallecido dicho señor sumaban 279.486 reales, mientras que los bienes del pazo de Oca se reducían a 18.385,2 reales; en la casa principal de Santiago, que había sido la residencia del señor y su familia hasta octubre de 1751, se hallaban bienes tasados en 7.349 reales, que se completaban con los existentes en la mayordomía, cuyo valor era similar al de los bienes de Ourense; y en último lugar se situaban las casas de Herbedelo y Sober, con un mobiliario mucho menor.

${ }^{24}$ El avance del llamado "proceso de civilización" durante la época moderna sería evidente en una gran parte de los pazos de la hidalguía gallega y, por supuesto, el grado de ostentación y lujo sería mayor en aquellos donde residían los hidalgos más ricos y poderosos, convertidos en grandes centros de consumo, de atracción de mano de obra y, en particular, de demanda artística. Vid., entre los trabajos que se han dedicado a analizar la estructura arquitectónica y, en general, los rasgos artísticos de estos pazos, MARTÍNEZ BARBEITO, Carlos, Torres, pazos y linajes de la provincia de la Coruña, León 1978; RIVERA RODRÍGUEZ, M. ${ }^{a}$ Teresa, Los pazos orensanos, A Coruña 1982; GARCÍA IGLESIAS, Xosé Manuel, Pazos de Galicia. Análisis documental, A Coruña 1992; PEREIRA MOLARES, Ana, Os pazos. Moradas fidalgas de Galicia, Vigo 1996; y, centrado en un pazo concreto, SÁNCHEZ GARCÍA, Jesús Ángel, Mariñán. Pazo de los sentidos, A Coruña 1999. 
Cuadro 1. Bienes muebles y semovientes inventariados al fallecer don Fernando Gayoso (Valor en reales de vellón)

\begin{tabular}{lrrrrrrr}
\hline & \multirow{2}{*}{ Valladolid } & \multirow{2}{*}{ Oca } & \multicolumn{2}{c}{ Santiago } & \multirow{2}{*}{ Ourense Herbedelo Sober } \\
\cline { 3 - 7 } & & & Palacio & Mayordomía & & & \\
\hline Coches y literas & 51.740 & - & 5.000 & 500,0 & - & - & - \\
\hline Ganado & 32.055 & 70,0 & - & 600,0 & - & - & - \\
\hline Iluminación & 6.438 & 56,0 & 4 & 15,0 & - & - & - \\
\hline Mobiliario & 12.481 & $6.072,2$ & 1.563 & 916,5 & 2.498 & 769 & 181 \\
\hline Objetos decorativos & 52.787 & $4.603,2$ & 703 & 797,0 & 526 & - & - \\
\hline Ropa de cama & 26.074 & $3.022,0$ & - & 56,0 & - & - & - \\
\hline Ropa de mesa & 2.224 & 32,0 & - & - & - & - & - \\
\hline Ropa de otros tipos & 3.469 & 256,0 & - & 380,0 & - & - & - \\
\hline Servicio de baño & 8.580 & 85,0 & - & - & - & - & - \\
\hline Servicio de cocina & 913 & 294,0 & - & 53,0 & - & - & - \\
\hline Servicio de mesa & 58.590 & 773,7 & - & - & - & - & - \\
\hline Utensilios agrícolas & - & 428,7 & - & - & - & - & - \\
\hline Varios & 24.135 & $2.692,5$ & 79 & 539,5 & 265 & - & - \\
\hline TOTALES & $\mathbf{2 7 9 . 4 8 6}$ & $\mathbf{1 8 . 3 8 5 , 2}$ & $\mathbf{7 . 3 4 9}$ & $\mathbf{3 . 8 5 7 , 0}$ & $\mathbf{3 . 2 8 9}$ & $\mathbf{7 6 9}$ & $\mathbf{1 8 1}$ \\
\hline
\end{tabular}

FUENTE: Elaboración propia a partir de inventarios postmortem (AHUS, Medinaceli, Amarante, 480, leg. 15, doc. 6)

En cuanto a la inversión de don Domingo Gayoso de los Cobos, aunque éste no mencionaba nada en su testamento, las cuentas de sus mayordomos de rentas mostraban a un señor que, aunque no siempre de forma voluntaria, también realizaría importantes obras, no sólo en sus principales casas solariegas, sino también en aquellas iglesias y capillas de las que era patrono y en otros edificios que se hallaban igualmente bajo su responsabilidad, como las cárceles jurisdiccionales. De este modo, los mayordomos de Amarante y Sober-Ferreira tuvieron que afrontar importantes desembolsos desde los años setenta hasta fines de siglo — sobre todo, en los setenta y noventa-, una época en la que también se acometerían obras de gran relevancia en la casa principal de Santiago, en otros edificios de esta ciudad, así como en el pazo de Oca, cuya huerta ya requería un elevada inversión para pagar los salarios de los trabajadores y jornaleros contratados para acometer los trabajos agrícolas ${ }^{25}$.

${ }^{25}$ Sobre las obras de Oca y las labores agrícolas realizadas en su huerta, que experimentaría una gran transformación durante el siglo XVIII, vid.: SAAVEDRA FERNÁNDEZ, Pegerto, "La vida en los pazos gallegos", 304 ss.; y, con un enfoque más general, LÓPEZ, Pedro, "Historia del pazo de Oca”, Boletín Auriense, 14 -15 (1986), 143-171. Y, en lo que se refiere al papel del jardín de los pazos gallegos, cf.: RODRÍGUEZ DACAL, Carlos - IZCO, Jesús, El jardín de los pazos gallegos. Espacio de recreo y fuente de recursos, Santiago 1994; y SÁNCHEZ GARCÍA, Jesús Ángel, "El jardín de una élite. Los Bermúdez de Castro y el pazo de Montecelo en los siglos XVIII y XIX", Universitas. Homenaje a Antonio Eiras Roel 2, Santiago 2002, 113-135. 
La fortaleza de Amarante sufriría un grave incendio a inicios de la década de los setenta que obligaría a realizar una importante inversión para acondicionar de nuevo las estancias que habían sido afectadas por el fuego, labor que se iniciaba en 1773, con el reconocimiento de los desperfectos por un maestro de carpintería y otro de cantería, y no se finalizaría hasta finales de dicha década, con la construcción de un nuevo cuarto, dos caballerizas, un cobertizo y un horno para el "casero" y su familia. Pero, además de las obras realizadas en la propia fortaleza, el señor también destinaría una parte de sus rentas a la construcción de una cárcel en el coto de Santa María de Gián, para lo cual se habían desembolsado 1.820 reales en 1769, y otra en la jurisdicción de Amarante, ya en los años 179798, y también invertiría más de 47.500 reales a la realización de obras y reparos en varias iglesias parroquiales de la jurisdicción de Amarante desde 1788 hasta fines de siglo, destacando las cantidades gastadas en las iglesias de San Julián de Facha, San Esteban do Castro de Amarante y Santa Eulalia de Árbol, tanto en "la fábrica de la iglesia" como en sus retablos y en todo lo demás necesario, con una inversión de más de diez mil reales en cada una de ellas ${ }^{26}$.

Una parte considerable de las rentas percibidas por los mayordomos de las casas de Sober y Ferreira durante los años setenta y primera mitad de la siguiente década se destinarían a costear las obras y reparaciones realizadas en el palacio de Sober y demás edificios anexos a él, como la capilla de Nuestra Señora del Rosario, de tal forma que entre los años 1772-83 se registraría un gasto total de 32.890,4 reales. En la fortaleza de Ferreira también se realizarían varias obras, pero serían menos costosas, destacando 8.191,32 reales desembolsados en el año 1776 para "armar la casa de Ferreira, su torre y faiados", incluyendo las cantidades gastadas para "subir los cañones a la pared del castillo". A ello había que añadir la construcción de la cárcel jurisdiccional de Sober en 1768, que tan sólo costaría 1.112 reales, los reparos realizados en ella hasta fines de siglo, que supondrían otros 799,5 reales, así como las diversas cantidades entregadas para obras en las iglesias de San Esteban de Refoxo, San Pedro de Sindrán y San Juan de Toldaos, que ascendían a 10.263 reales, y aquellas otras invertidas en la conservación de bodegas, lagares y otros bienes que también formaban parte del patrimonio de las casas de Sober y Ferreira (Vid. Cuadro 2).

Igualmente, don Domingo Gayoso de los Cobos también acometería importantes obras en la casa principal de Santiago, una de las tres residencias en las que viviría entre los años 1765 y 1797, así como en otros edificios que poseía en dicha ciudad, algunos de ellos comprados por él mismo, reparados y, posteriormente, arrendados. Así, entre el 10 de junio de 1786 y el 3 de marzo de 1788 se

26 AHUS, Medinaceli, Amarante, 483 y 484, leg. antiguo 8 (Contabilidades de los mayordomos de la casa de Amarante para los años 1765-1801). 
realizarían obras en dicha casa por un importe total de 193.239,29 reales, unas obras que continuarían en años sucesivos y durante toda la década de los noventa, si bien las cantidades destinadas a estos fines en los últimos años del siglo ya serían menos relevantes: entre el 17 de octubre de 1797 y el 30 de noviembre de 1798, por ejemplo, tan sólo se gastarían 33.998,71 reales, de los cuales 17.482,65 se habían invertido en "la obra que se hizo en las casas inmediatas a la principal" y la cantidad restante se había destinado a pagar obras y reparos menores realizados en los edificios, así como en mobiliario y otros objetos de uso cotidiano, que poseía en la ciudad de Santiago y el coto de Oca, destacando 5.932 reales pagados a un pintor — don Juan Bernardo del Río—, 3.770,30 recibidos por un herrero - Vicente Samoeda - y otros 3.311 adeudados a un guarnicionero Manuel Barona- que había reparado uno de los coches del señor ${ }^{27}$.

\section{LA SITUACIÓN A PRINCIPIOS DEL SIGLO XIX}

El gran número de mayorazgos agregados durante el siglo XVIII permitiría que los condes de Amarante pudieran realizar una importante inversión en la reparación y conservación de las diversas casas solariegas que poseían en Galicia, tierra en la que residirían durante una gran parte de sus vidas, siendo la ciudad de Santiago su principal lugar de habitación. Doña Constanza Arias Ozores y su esposo don Andrés de Gayoso serían los primeros condes de Amarante avecindados en dicha ciudad, aunque también pasarían largas temporadas en el pazo que poseían en la feligresía de San Esteban de Oca. Don Fernando Gayoso, hijo de los anteriores, y su esposa doña María Josefa de los Cobos también residirían en Santiago y Oca hasta octubre de 1751, fecha en la que esta pareja se trasladaba a la ciudad de Valladolid, donde fallecería don Fernando Gayoso. Asimismo, don Domingo Gayoso de los Cobos, como habían hecho sus padres y sus abuelos, también pasaría casi toda su vida en territorio gallego, residiendo en Santiago, Oca y, también, A Coruña; pero en octubre de 1797 se trasladaría con su esposa a la villa de Madrid, en donde fallecería el día 4 de septiembre de 1803, con setenta años, siendo enterrado "de secreto" en la iglesia de San Luís, junto a su esposa y a su segundo hijo varón, fallecido apenas un año antes ${ }^{28}$.

\footnotetext{
27 AHUS, Medinaceli, Santiago, 275, leg. antiguo 6 (Libro cobrador de 1774); y 277, leg. antiguo 7 y 282, leg antiguo 8 (Cuentas de 1784-88 y 1797-98).

28 AHUS, Medinaceli, Amarante, 481, leg. 16, doc. 47 (Testamento otorgado por don Domingo Gayoso en Madrid el 2 de septiembre de 1802); e Indiferente, 187, fotograma 418 (Partidas de defunción de don Domingo Gayoso, su esposa y su segundo hijo).
} 
Cuadro 2. Cantidades gastadas en obras por los mayordomos de Sober-Ferreira entre 1766 y 1800 (Reales de vellón)

\begin{tabular}{lr}
\hline Lugar & Cantidad \\
\hline Palacio de Sober y sus anexos & $47.047,08$ \\
\hline Iglesias de Refoxo, Sindrán y Toldaos & $10.263,00$ \\
\hline Fortaleza de Ferreira & $9.980,32$ \\
\hline Bodega y lagar en Santa Eulalia de Teilán (en Bóveda) & $3.169,44$ \\
\hline Cárcel jurisdiccional de Sober (en Proendos) & $1.911,50$ \\
\hline Cercado de una dehesa (“dehesa do Castro”) & $1.100,00$ \\
\hline Cercado de un prado (“prado de Vizcaya”) & 612,00 \\
\hline Otros lugares & 119,50 \\
\hline Total & $\mathbf{7 4 . 2 0 2 , 8 4}$ \\
\hline
\end{tabular}

FUENTE: Elaboración propia a partir de cuentas de los mayordomos de Sober-Ferreira para los años 17661800 (AHUS, Medinaceli, Amarante, 485 y 486, leg. antiguo 9)

En cualquier caso, a pesar de la importante inversión realizada durante el siglo XVIII, las casas heredadas por don Joaquín Gayoso de los Cobos, hijo primogénito de don Domingo Gayoso, aún presentaban cuantiosos desperfectos a inicios del siglo XIX. Como se puede ver en el cuadro 3, estos desperfectos se valoraban en 404.995 reales de vellón, una gran parte de los cuales debían gastarse en algunas de las casas existentes en Santiago: una casa usada como almacén y pajar, que lindaba con el palacio reparado por el difunto don Domingo Gayoso y que había sido incluida en el proyecto de obra de aquel, en donde debían invertirse 114.031 reales; otras dos casas sitas en la misma calle de la Algalia de Abajo, una habitada por dos mujeres y con desperfectos valorados en 2.135 reales, y otra "quasi enteramente en el suelo", en cuyo solar aún se hallaban los restos de las obras hechas en el palacio, que requería una inversión de 18.652 reales; y, por último, otras tres casas situadas en la calle de Entremuros, que confinaban con un horno que también era del señor y se hallaba aforado, en las cuales era necesario realizar reparos por un valor total de 4.092 reales.

Entre las casas solariegas propiamente dichas, los desperfectos más cuantiosos se encontraban en el palacio de Sober, con un valor de 57.000 reales, la mayor parte de los cuales debían invertirse en la reparación de una pared derruida, de la chimenea de la cocina, que era aconsejable colocar en otra parte del palacio, y del armazón de "los tres altos, que se entienden terreno, primero y segundo piso, que es el de los fayados"; y en la fortaleza de Ferreira, que "a no ser algunos reparos que se han hecho de nuevo, ya estubiera todo este edificio arruinado por su 
antigüedad", era necesario realizar obras por un valor de 36.180 reales $^{29}$. Como Sober y Ferreira, las casas de San Miguel de Penas y San Pedro de Meixide estaban a cargo de un mismo administrador y, por ello, sus desperfectos se reconocían conjuntamente, aunque en San Miguel ascendían a 18.800 reales, mientras que en Meixide se limitaban a 10.350 reales. Entre veinticinco y treinta mil reales se situaban los desperfectos de las casas de Cillobre, Torés y Mañón, mientras que en La Mota y Junqueras no llegaban a veinte mil y en las demás casas apenas superaban los cinco mil reales.

Cuadro 3. Tasación de los desperfectos de las casas del conde de Amarante a inicios del siglo XIX (Reales de vellón)

\begin{tabular}{lr}
\hline Casas & Tasación \\
\hline Seis casas en la ciudad de Santiago & 138.910 \\
\hline Palacio de Sober y fortaleza de Ferreira & 98.980 \\
\hline Casas de San Miguel de Penas y San Pedro de Meixide & 29.150 \\
\hline Fortaleza de Cillobre y anexos (capilla, casa da Fraga y casa da Viña) & 28.500 \\
\hline Fortaleza de Torés y bienes anexos a ella & 27.210 \\
\hline Pazo de Mañón, en Lagostelle (Guitiriz) & 26.496 \\
\hline Casa de San Esteban de La Mota & 19.130 \\
\hline Fortaleza de Junqueras y casa de la audiencia-cárcel del Caramiñal & 13.728 \\
\hline Palacio de la Mela, en Covelo & 5.697 \\
\hline Torre de Santiago de Fazouro, en Mondoñedo & 5.680 \\
\hline Pazo de Oca & 4.530 \\
\hline Casa y torre de Parga & 4.224 \\
\hline Capilla y casa cárcel del coto de San Pedro de Roupar & 2.760 \\
\hline TOTAL & $\mathbf{4 0 4 . 9 9 5}$
\end{tabular}

FUENTE: Elaboración propia a partir de los reconocimientos hechos en el año 1804, tras la muerte de don Domingo Gayoso de los Cobos (AHUS, Medinaceli, Indiferente, 187, fotogramas 466 y ss.)

${ }^{29}$ Los maestros de cantería y carpintería que habían reconocido el palacio de Sober y la fortaleza de Ferreira también reconocerían la capilla de Sober, no hallando en ella desperfectos de consideración, la capilla de Ferreira, en la que se requerían 4.000 reales para reparar su retablo, su armazón y su tejado, la cárcel de la jurisdicción de Sober, para la que el carpintero decía que se necesitaban 1.500 reales, y "la bodega que se llama de Martur, adonde se recoge la sincura de S.E. de San Esteban de Refoxo", en la que se requerían otros 300 reales para poner dos vigas nuevas. Todo ello, junto con los desperfectos arriba mencionados, sumaba un total de 98.980 reales. Vid.: AHUS, Medinaceli, Indiferente, 187, fotograma 466 (Reconocimientos y tasaciones de "los desperfectos, mejoras y fincas libres encontrados en los estados de Amarante, Parga y San Miguel de Penas"). 
La inversión en obras, por tanto, tendría que continuar durante el siglo XIX, pero en esta centuria ya no se acumularían más rentas mediante la agregación de mayorazgos y la Guerra de Independencia y, posteriormente, las transformaciones introducidas por la legislación liberal afectarían a los ingresos de don Joaquín Gayoso de los Cobos, que no podría realizar inversiones tan relevantes como sus predecesores $^{30}$. Los estados que don Joaquín había heredado en Castilla, Cataluña, Aragón y Andalucía serían ocupados por los franceses y, como indicaba su apoderado general de la ciudad de Santiago en 1812, durante varios años tendría que costear todos sus gastos casi exclusivamente con las rentas de sus estados de Galicia, "agregándose a todo ello que con los superiores decretos de abolición de señoríos cesaron y continuamente están cesando varios pagos que, en cierto modo, podrían cubrir parte de los gastos forzosos de las casas de S.E."; y, además, sus administradores tampoco podrían percibir con regularidad muchas de las rentas que aparecían en sus libros cobradores ${ }^{31}$.

El propio don Joaquín Gayoso de los Cobos reconocía su situación en algunas de las cartas remitidas a sus administradores. A inicios de 1828, por ejemplo, contestaba a una solicitud para un puesto vacante de administrador indicando que se veía obligado a "hacer novedad en algunas de las administraciones de aquel propio reino", no sólo por el mal comportamiento y desidia de varios de los administradores, sino también por "la decadencia de mis rentas por el despreciable valor que ha años tienen los frutos, no menos que por las vicisitudes que desgraciadamente han cogido a los propietarios $\mathrm{y}$, en especial, a los de mi clase"; y apenas un año más tarde, en una carta remitida a uno de sus administradores, afirmaba que se hallaba "en la indispensable necesidad de aceptar cuantas medidas de economía estén al alcance, en razón de nivelar los precisos gastos de mi casa con lo que en el día dan de sí las rentas de mis estados", razón por la que había decidido "reunir en una sola las administraciones de Amarante, San Miguel de Penas y Meijide", destituyendo a los administradores existentes — uno para Amarante y otro para San Miguel y Meixide - y

\footnotetext{
30 Sobre la aplicación de la legislación liberal en Galicia y las consecuencias que tendría para su estamento nobiliario, vid.: VILLARES PAZ, Ramón, La propiedad de la tierra en Galicia, 15001936, Madrid 1982, 142 ss.; BAZ VICENTE, M. ${ }^{a}$ Jesús, El patrimonio de la casa de Alba en Galicia en el siglo XIX, Lugo 1991; ídem, Señorío y propiedad foral de la alta nobleza en Galicia (siglos XVI-XX): La Casa de Alba, Madrid 1996, 227 ss.; DOMÍNGUEZ CASTRO, Luís, Viño, viñas $e$ xentes do Ribeiro. Economía e patrimonio familiar, 1810-1952, Vigo 1992; MIGUÉS RODRÍGUEZ, Vitor M., As terras, as pousas e os vinculeiros, 446 ss.; y PRESEDO GARAZO, Antonio, A fidalguía galega ante a crise do Antigo Réxime (1812-1868), Santa Comba-A Coruña 2006.

31 Entre las rentas que no se percibirían en estos años se hallaban los diezmos, que en Galicia constituían su segunda fuente de ingresos, después de las rentas forales. Vid.: AHUS, Medinaceli, Santiago, 271, leg. antiguo 1, doc. 15 (Expediente sobre el reparto de la Contribución Extraordinaria de Guerra del año 1812); y, sobre los efectos de la abolición de los diezmos para la nobleza gallega, BAZ VICENTE, M. a Jesús, Señorío y propiedad foral, 266-71.
} 
nombrando en su lugar a uno sólo, el cual tendría su residencia en la fortaleza de Amarante ${ }^{32}$.

Esta reducción del personal administrativo suponía que algunas de sus casas se quedarían totalmente deshabitadas, siendo utilizadas únicamente sus paneras, tullas y bodegas para beneficiar las rentas, una situación que no cambiaría con los sucesores de don Joaquín Gayoso de los Cobos. Éste fallecería en Madrid el día 6 de mayo de 1849 y sus siete hijos dividirían el patrimonio de acuerdo con la ley de mayorazgos de agosto de 1841, pero algunas de sus casas solariegas permanecerían indivisas durante una gran parte del siglo, sin que hubiese un único titular que se encargase de costear la reparación de sus desperfectos. Según un inventario del año 1898, en esta situación se encontraban los siguientes edificios: la "torre de Cillobre", con su planta baja, piso y graneros, así como "horno, cuadras y tendal separado de la misma", todo cerrado con muro alto; la casa "llamada torre de Parga", colindante con un huerto y unas "ruinas de la torre"; el "palacio" de Amarante, con su huerta; "las ruinas de una fortaleza" en Torés, además de una cárcel, una panera y diversos terrenos; "un edificio ruinoso denominado de San Miguel de Penas, situado en el pueblo de este nombre"; una "casa tulla" en Gián; y "una casa para recoger granos" en Moreiras ${ }^{33}$.

32 AHUS, Medinaceli, Curatos, 300 (Nombramientos de administradores).

33 De todos estos edificios, aquellos que tenían un mayor valor eran la torre de Cillobre, tasada en 6.250 pesetas, el palacio de Amarante, valorada en 3.000 pesetas, y los bienes de Torés, que suponían otras 3.830 pesetas. Vid.: AHUS, Medinaceli, Indiferente, 200, fotograma 145 (Relación e inventario de bienes indivisos de don Joaquín Gayoso de los Cobos). 